\title{
Comentarios
}

\section{Releyendo la plataforma económica}

Si a inicios de enero lo sorpresivo de las medidas económicas anunciadas generó el desconcierto y el cuestionamiento, ahora es más bien lo sorpredente de dichas medidas lo que está generando una reflexión positiva. No es el gobierno, ni su comité económico, el sujeto activo de esta reflexión, aunque sí han sido forzados a ello, desde dentro y desde fuera, a aceptar que su plataforma económica no puede funcionar con la armonía y sincronización de un mecanismo de relojería. Por decisión suprema o por limitaciones técnicas, el ejecutivo no ha presentado un plan de desarrollo económico y social realista, asentado en un análisis estructural y multisectorial de nuestro modo de producción que oriente la programación del mediano plazo. De ahí lo sorpresivo y sorprendente de las medidas anunciadas.

El presidente de la república habla de una "plataforma ecconómica para el desarrollo social". Plataforma económica no es lo mismo que plan de desarrollo. En la rampa de lanzamiento de esta plataforma se ajustarían las cuatro o cinco medidas economicas y en un tiempo, aun sin precisar, se lograría "mejorar la calidad de vida de la población y convertir a El Salvador en un país de oportunidades para todos con equidad". Como postdata, el presidente agregó que tales medidas "son un aporte al costo de los acuerdos de paz" y que "van a generar más empleo, bienestar, salud, vivienda y desarrollo".

El enunciado de estas gloriosas profecías ha gestado una doble vertiente de reflexiones. Reflexiones, en primer lugar, sobre la idoneidad de las medidas propuestas y de manera especial sobre la sincronización armónica de la relojería macroeconómica. En segundo lugar, y tanto o más importante, se cuestiona la virtuosidad de la plataforma económica para dar el salto cualitativo hacia el bienestar social con equidad. Lo positivo de estas reflexiones es que proceden de un conjunto heterogéneo de asociaciones empresariales, laborales y sindicales, universidades, centros de investigación, iglesias y otras instituciones, que a diario se manifiestan, aunque no a todas se presta la misma atención. Diríamos que entre todos redescubrimos nuestra realidad, en sus diversos órdenes, con sus logros y sus limitaciones mayores. Entre todos se le está indicando al gobierno por dónde debe comenzar y por dónde debe encaminarse un plan de desarrollo, acorde al tiempo y a la geografía en que estamos ubicados.

Aparte de los tecnicismos que puedan aparecer en todas estas reflexiones, las páginas acumuladas en los diarios y en los espacios de la televisión se han convertido en cursos actualizados de economía aplicada. Sería de lamentar que frente a esta multiplicidad de aportes, las autoridades económicas se comporten como el gobierno del diálogo que no escucha a nadie. La intención de estas breves páginas no es volver a los tecnicismos, sino recoger algunas reflexiones sobre las medidas en sí mismas y sobre su virtuosidad para desembocar en el mayor bienestar social con equidad.

Inicialmente, el desconcierto y el cuestionamiento pudieron nacer de la desafortunada afirmación de que El Salvador se convertiría en una am- 
plia zona franca. Los sectores no ubicados en la desembocadura final del proceso productivo vieron amenazada la suerte futura de sus empresas, situadas en la función suministradora y transformadora del producto nacional. Ningún miembro del comité económico gubernamental se apresta a repetir ahora la misma profecía. Los desagradables hechos de enero y febrero han sido el botón de muestra de que nuestras maquilas no son, hoy por hoy, la mejor solución tecnológica, económica y social, ni modelo de inversión extranjera, ni multiplicador del bienestar nacional.

El cuestionamiento avanza ahora hacia la oportunidad de las propias medidas y se enfrenta con el dogmatismo de sus progenitores. Nos acercamos al tema de la transparencia con que las autoridades han conducido el proceso de consultoría de las medidas propuestas. En el apartado de "Economía y negocios" de El Diario de Hoy (2 de febrero de 1995 , p. 17) se trasluce, en resumen, la reunión sostenida por varios miembros y asesores del comité económico con representantes del Fondo Monetario Internacional (FMI), del Banco Mundial (BM) y del Banco Interamericano de Desarrollo (BID). La reunión tuvo lugar en Washington, el pasado mes de noviembre. El título invita a leer todo el comentario: "Dijeron organismos al gobierno: ningún país ha eliminado los aranceles". Se trata de un documento "confidencial", pero las confidencias se resumen en observaciones a cada una de las medidas económicas. Estos organismos internacionales mostraton algunos reparos, junto con la recomendación de modernizar al Estado. Algunos de los reparos aparecen como breves frases sueltas, pero suficientemente indicadoras de la inoperancia de la medida, como lo han hecho ver recientemente otros técnicos nacionales. He aquí un resumen.

Michael Bruno (FMI) expresó que la adopción del currency board significaba "atarse las propias manos y perder la capacidad de reacción ante choques negativos externos. ¿Qué pasará cuando el ciclo económico de Estados Unidos se haga negativo? ¿Cómo se ajustará la economía?". Por lo que se refiere a las altas tasas de interés, el hecho puede obedecer a "la estructura oligopólica del sistema financiero". El ejemplo del currency board de
Argentina no sirve porque "lo hizo porque no poseía credibilidad en los círculos financieros internacionales y ésa era la única opción que le quedaba". La delegación nacional pudo observar que no recibía el beneplácito internacional para el currency board. Pero quedaba siempre la opción del cambio fijo.

Sin alargarnos en explicaciones y tecnicismos son muchas las voces autorizadas que se han pronunciado contra el cambio fijo, con o sin currency board. Unos ejemplos a modo de ilustración. Edgardo Suárez, antiguo presidente del Banco Central de Reserva, viene a decir, en resumen, que fijar por decreto un tipo de cambio fijo "equivale a poder dominar por decreto las variables reales y monetarias que hacen posible estabilizar el tipo de cambio". Un tipo de cambio fijo presupone que el país, o su banco central preferiría decir yo, debiera tener una cantidad y una oferta de dólares ilimitadas, para en todo momento estar dispuesto a venderlos por colones e incluso para estar dispuesto a perder reservas netas. Pero además, por convenios de triangulación centroamericana, también para estar dispuesto a vender dichos dólares por lempiras, quetzales y córdobas. Presupone, además, que no debería existir ningún desequilibrio financiero en el país, provocado ya sea por un déficit fiscal, por la disminución de las remesas familiares o por la disminución de las entradas de capital, préstamos y donaciones, que compensen el preocupante y creciente déficit comercial que ya tenemos.

Y por último, que la producción nacional tenga las caraterísticas de una verdadera reconversión agroindustrial, con una infraestructura apropiada y con los recursos humanos bien capacitados para competir con gallardía en el mundo globalizado en que vivimos, "al no darse este conjunto de premisas, la fijación de un tipo de cambio fijo equivaldría a decretar un nuevo mercado negro de divisas" (La Prensa Gráfica, 20 de enero de 1995, p. 10-A). Nos hemos alargado en la cita por ser éste el argumento central en contra del tipo de cambio fijo en las actuales circunstancias.

Han sido repetidas las intervenciones de Juan Héctor Vidal (ANEP) rechazando la oportunidad del cambio fijo, desde su enfrentamiento en televi- 
sión con el segundo vicepresidente del Banco Central de Reserva, Gino Betaglio. Bajo el título "ANEP refuta el Banco Central", se recogen los mismos argumentos: no es el tipo de cambio fijo el que va a equilibrar el déficit fiscal, las tasas de inflación y los intereses bancarios, sino que la recomposición de estas variables genera la credibilidad monetaria (El Diario de Hoy, 13 de enero de 1995, p. 15). Más detalladamente se expresa en la página de "Opinión”, “¿Cambio fijo? Si quieren recorremos de nuevo el camino andado. Pero además...". Nos bastarían prácticamente los dedos de una mano para contar los países afiliados al currency board, una situación que en algunos casos se deriva del coloniaje inglés o norteamericano.

Juan Héctor Vidal concentra en un párrafo el cuestionamiento de esta medida que tiende a convertir el efecto en causa. "El mérito que se atibuye al currency board de que por sí mismo garantiza el control de la inflación y el crecimiento sostenido, implica que se ha dado respuesta a cuestiones como las siguientes. Primero, que están dadas las condiciones en materia de una base tributaria que provea al fisco de ingresos crecientes y ciertos, manejo responsable y eficiencia administrativa para que las finanzas públicas en general no den lugar a déficits que presionen constantemente la demanda agregada. Además, que se tienen las bases institucionales y jurídicas para garantizar que el crédito público y privado se manejan con criterios técnicos y no políticos y en función del país y no de intereses sectoriales. Asimismo, de que hay garantía de un flujo constante de divisas generadas en fuentes autónomas y predecibles y no en aquellas que, como las remesas familiares, pueden tornarse eventualmente volátiles; de lo contrario, la economía del país se vería a menudo expuesta a ciclos recesivos ante la variación drástica de los niveles de las reservas intemacionales. $\mathrm{A}$ la inversa, habría que preguntarse ¿cómo se enfrentaría con el currency board la sobrevaluación cambiaria que ocasionan los crecientes flujos de remesas familiares, sin afectar la competitividad de las empresas nacionales?" (La Prensa Gráfica, 8 de enero de 1995 , p. $8-A)$.

Días más adelante, Juan Héctor Vidal responde

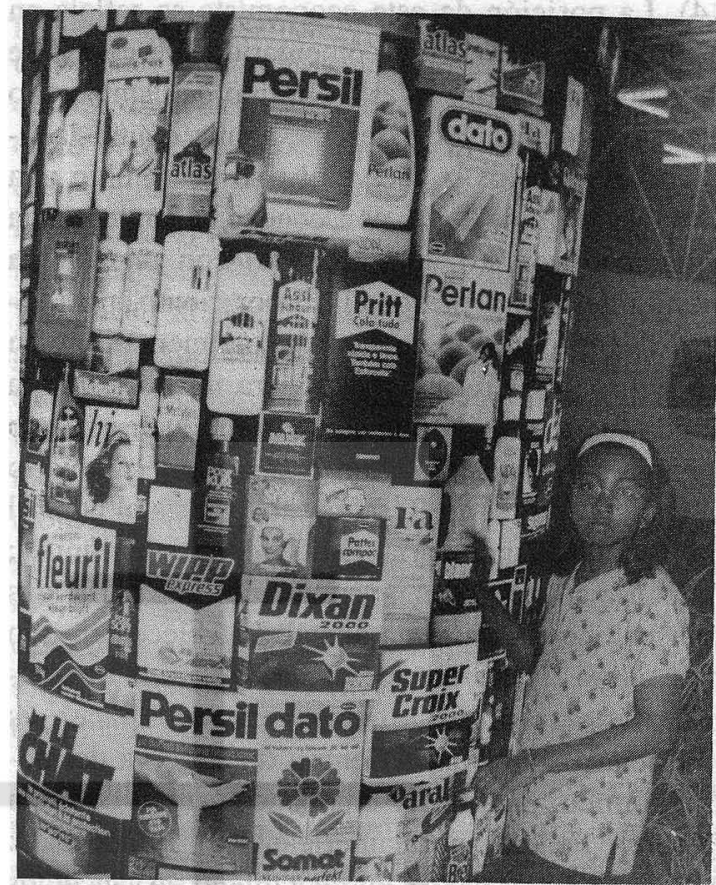

al doble argumento adicional con que las autoridades del Banco Central de Reserva argumentan la necesidad del cambio fijo: las pérdidas operativas en que incurre el banco central con las operaciones de mercado abierto (compra-venta de bonos de corto plazo, CEM), así como el peligro de la sobrevaluación del tipo de cambio derivado de los altos precios del café. "Lo de las pérdidas operativas y la preocupación por los ingresos extraordinarios del café, precisamente lo que sugieren es la debilidad de nuestro sistema económico para adaptarse rápidamente a situaciones cambiantes generadas en el sector externo. De allí la duda que nos surge de que podamos sostener por largo tiempo el tipo de cambio frente a un shock externo de grandes proporciones o ante un déficit fiscal que se vuelva crónico por fenómenos exógenos o por falta de disciplina fiscal" (La Prensa Gráfica, 18 de enero de 1995, p. 10-A).

Vale la pena citar finalmente el comentario de Luis Membreño, quien por primera vez sacó de la clandestinidad el programa que se venía gestando: "Proponen nuevo plan de ajuste económico". Este artículo, que sacudió la atención pública porque anunciaba las cuatro medidas principales, apareció en El Diario de Hoy, el 13 de octubre de 1994 (p. 
14). La posición de este economista se refleja en el título de su reciente comentario: "Se comparte la visión, no las medidas". Un tipo de cambio fijo "conlleva demasiados riesgos, atenta contra la libertad de precios y vuelve al tipo de cambio una variable política". En consecuencia, sugiere una flotación sucia (o administrada) con una banda amplia de más o menos el 10 por ciento, para lograr llegar a un tipo de cambio totalmente libre en un futuro. "Si el gobierno tuviera miedo a que la banda fuera muy amplia se podría reducir a más o menos el 5 por ciento. Con este sistema cambiario el Banco Central de Reserva recuperaría el control de la política monetaria, dentro de ciertos límites; reduciría sus pérdidas operacionales y le daría más transparencia al sistema actual. Establecer un tipo de cambio fijo es retroceder en el camino que hemos recorrido. Lo que deberíamos hacer es independizar al Banco Central de Reserva del poder político, para hacer una banca central como la Reserva Federal norteamericana, el Bundesbank alemán o un Banco Central chileno. Avancemos mejor en la línea de la división de poderes, que garantizará mejor la estabilidad económica y social del país" (El Diario de Hoy, 18 de enero de 1995, p. 13).

El comentario de Luis Membreño se sitúa en la línea de autonomía y responsabilidades monetarias, crediticias, financieras y cambiarias que la ley orgánica vigente del Banco Central de Reserva le confiere como banco de la nación. Desconocemos cuáles de estas funciones permanecerían o desaparecerían si el banco se redujera a un controlador mecánico de la hidraúlica o liquidez monetaria. Ya la misión alemana del IPC, que en 1989 asesoró el proceso de la reforma financiera y bancaria, insistió en la autonomía política del Banco Central de Reserva, en la constitución de un marco normativo controlado por la Superintendencia (también autónoma) del Sistema Financiero y en una administración técnica de estas instituciones. Todas ellas han estado operando deficientemente por diversos motivos, tanto en el proceso de privatización como en el de nacionalización bancaria. La misma Asociación Nacional de la Empresa Privada (Correo Económico, octubre de 1994) afirma que el actual sistema bancario discri- mina políticamente el crédito, frenando así el desarrollo de los sectores productivos y favoreciendo al sector comercial y de servicios por sus mayores y más rápidos márgenes de ganancia. Es la terciarización económica.

Nuestro departemento de economía se ha centrado específicamente en las consecuencias económicas y sociales de fijar el tipo de cambio en 8.75 colones por dolar, mostrando en el artículo cuáles son los sectores beneficiados y perjudicados, en particular el deterioro del poder real de compra de. los salarios populares. Parecía necesario recoger, sin mayores tecnicismos, algunos comentarios autorizados, externos e internos, que induzcan a los asesores gubernamentales a dialogar y a escuchar, antes de procrearnos, en seis o en nueve meses, un currency board enfermizo. Implícitamente, las reflexiones monetarias nos redescubren nuestras debilidades en el sector real de la producción.

Tanto la propuesta del currency board como la anunciada desgravación de aranceles nos han obligado a hacer apreciaciones y autocríticas más sinceras de nuestra capacidad tecnológica y competitiva. Las tantas veces mencionadas remesas familiares (mil millones de dólares en 1994) nos recuerdan que entre el 25 y el 30 por ciento de la demanda nacional no es cosecha de la productividad interna, sino un patriótico shock externo.

Volviendo a la reunión sostenida en Washington, en noviembre de 1994, los representantes del Fondo Monetario Internacional, del Banco Mundial y del Banco Interamericano de Desarrollo cuestionaron la viabilidad política de la reducción de los aranceles y del incremento del impuesto al valor agregado. La razón es breve y cierta: "También dudaron que existieran suficientes estudios técnicos en los que se apoyaran ambas medidas". Volvemos a lamentar que el actual gobierno no haya preparado y no haya publicado un plan de desarrollo, fundamentado en un análisis estructural e intersectorial del entramado económico. Esta deficiencia es tanto más de lamentar por el hecho de que el Banco Central de Reserva ha publicado en 1993 la matriz insumo-producto de 1990 y está preparando la emisión de las matrices de 1991, 1992 y 1993. 
Lastimosamente, este gran esfuerzo y gasto económico pasarían al rublo de los "inventarios". De hecho, existe una base para los estudios técnicos requeridos en Washington. La desgravación arancelaria anunciada ha obligado a aceptar que en nuestra economía, en plural, las diversas ramas productivas no están ni tan recuperadas ni tan consolidadas como lo publicitaban los portaestandartes de la economía del mercado. Involuntaria y privadamente se está haciendo un bosquejo de matriz insumo-producto.

Las anunciadas reducciones arancelarias nos ayudan a mirar hacia el pasado y hacia el futuro. La protección a la industria naciente se tradujo en elevados aranceles y en exenciones fiscales en las décadas de 1960 y 1970. La prolongada protección externa y la concentración del crédito interno aletargaron el proceso de tecnificación y de calidad productiva, castigando con precios elevados y productos dudosos al consumidor nacional. Los elevados márgenes de ganancia se destinaban a beneficiar al empresario y no tanto a las empresas o a la reconversión industrial. Pocas empresas nacionales han podido utilizar la consigna "Si es Bayer, es bueno". En repetidas ocasiones han fracasado los intentos para imponer el control de calidad.

Adicionalmente, el inicio de las convulsiones sociales en la década de 1970 y su profundización en la larga década de guerra han cuasi anulado la inversión productiva en las áreas agropecuarias y manufactureras. En la presente década de los noventa, avanzamos entre claroscuros tecnológicos. Contamos con más de cuarenta así llamadas universidades para formar dirigentes, pero bastan los dedos de una mano para contar las escuelas profesionales relevantes. La micro y pequeña empresa se han convertido en la escuela doméstica de aprendizaje. La ley y Comisión Nacional de Ciencia y Tecnología y los programas de la Asociación Salvadoreña de Industriales para promover la reconversion industrial han rendido, de momento, efectos limitados. Se percibe un signo positivo en la parte creciente de los bienes intermedios y de capital dentro del conjunto de las importaciones.

A esta situación de mediano plazo se agrega el proceso de terciarización económica, en parte pro- piciado por el oligopolio bancario y la gran especulacion inmobiliaria y comercial. Las instituciones monetarias privadas buscan ganancias de corto plazo, mientras que las inversiones agrarias e industriales de postguerra se darían en el mediano plazo y pocas pueden enfrentan los elevados intereses activos. Estos mismos intereses se convierten en aranceles monetarios elevados para la pequeña empresa del sector informal. Por esta sumatoria de acciones se ha resentido la cadena de la integración económica interna agro-industrial, a todo lo cual se agrega el rezago tecnológico. De momento, los crecimientos globales de la economía no logran corregir esta desarticulación sectorial, ni los pretendidos proyectos de las zonas francas corrigen tal desarticulación, ni transmiten un impacto tecnológico "río arriba", hacia los sectores típicamente oferentes y transformadores.

También es necesario situar la cadena intersectorial en el espacio geográfico. Nuestra estructura mono u oligoexportadora, sumada al conflicto bélico, ha generado una acumulación urbana y una desolación campesina, concentrando en la primera zona la mayoría de los servicios públicos y privados, dejando en gran abandono al amplio sector primario. Basta leer los programas y proyectos de inversión física y social del plan de reconstrucción nacional (1991-1992) y del Fondo de Inversión Social para apreciar que existen dos El Salvador.

En este escenario sectorial y espacial debería fundamentarse un plan de desarrollo económico y social, así como debe ser considerada la compleja aplicación de las desgravaciones arancelarias. ¿Cómo se logra presionar con la discriminación y la gradualidad arancelaria a aquellos sectores que, por el bien del consumidor final, deben hacerse técnica y competitivamente productivos? ¿Cómo proteger con aranceles y crédito financiero, amén de otras reformas, a aquellos sectores que inculpablemente se verían arrasados por una apresurada apertura comercial? ¿Cómo organizar la formación humana profesional de los amplios sectores sometidos tradicionalmente al Decreto 187 salvadoreno? Este no es problema del sector privado o del sector público, sino que es problema y culpabilidad de todos nosotros.

Sentimos que el excesivo énfasis en la apertura 
externa, en el hacia fuera, corre el peligro de distraernos de la desintegración sectorial y espacial internas. Tampoco las tasas globales de crecimiento nacional deben generar el síndrome de ser los líderes regionales. En ciertos aspectos externos la tasa de crecimiento, la disponibilidad de divisas, ¿son nuestras?, el ritmo de la inflación "oficial".- nos podemos colocar en la categoría de primus inter pares, los primeros entre semejantes. Lo macroeconómico no puede deslumbrar lo estructural.

Estas consideraciones no quitan que haya aspectos positivos en las medidas anunciadas de modernización y descentralización estatal, en la gradualidad y la discriminación de las desgravaciones arancelarias, en la vigilancia de las causales de la inflación y en las promesas de mayor inversión en las ramas sociales. El propio gobierno se ha abstenido de mencionar el alza del impuesto al valor agregado, porque, en este punto, la oposición ha sido general, exceptuando quizás al nuevo Ministro de Hacienda. Más controversial, en los medios de comunicación social y en las calles de la capital, ha sido la propuesta de privatización de los activos nacionales. Sobre este espinoso tema nos remitimos al artículo de nuestro departamento de economía.

Las agujas de un reloj no caminan en dirección contraria la una respecto de la otra. En 1995, nos acordamos de las cosas dichas en 1994. La plataforma económica difícilmente conducirá a una equidad social si las agujas de los otros poderes públicos avanzan en sentido contrario. Precisamente, en 1994, salieron a la luz pública lacras políticas de vieja raigambre. Se trató de silenciar al informe de la Comisión de la verdad, pero no se pudieron acallar las repetidas acusaciones de corrupción, tráfico de influencias, inseguridad genralizada, condescendencia frente a claros delitos civiles y penales (lavado de dólares, narcotráfico y otros tráficos, etc.). La verdad sigue siendo la gran víctima de guerra y de postguerra.

Si el sector público acusa al sector privado de poca eficiencia productiva, el sector privado le devuelve el boomerang y pocas son las instituciones públicas que pueden librarse del golpe. Dada esta infra o superestructura cívico política tan regresiva, las simples medidas macroeconómicas no van a jugar limpiamente y menos aún a favor de la equidad social mayoritaria.

Los mismos análisis económicos ya señalan los sectores beneficiarios (el sector financiero, el comercial y ciertos exportadores...) y los sectores que claramente se sienten amenazados, integrando amplios grupos laborales del campo y de la ciudad. Al igual que el editorial de Proceso ( $\mathrm{N}_{-}$648) vemos en estas medidas una "aventura económica" y una desventura social. Las clases laborales, al igual que el sencillo campesino, tienen buen olfato para predecir los signos del tiempo. Las críticas más bien técnicas antes mencionadas, ponen en duda la sincronización armónica de esa relojería macroeconómica. El sentir popular y de tantas instituciones sociales apunta a que esas medidas por sí mismas no harán del "ser humano, centro y sujeto primordial del desarrollo" (Pacto de Managua, octubre de 1994).

La inversión en salud, educación, empleo, vivienda o calidad de vida sigue siendo insuficiente, aunque se promete incrementarla. Pero nos queda siempre una interrogante que, en la lógica de la economía de mercado, llaman "función subsidiaria del Estado". ¿Tranquilizamos nuestras conciencias colectivas con este calificativo? Tal vez la aparición de estas páginas coincida con la Cumbre Mundial sobre Desarrollo Social, que tendrá lugar en Copenhague (Dinamarca), del 6 al 12 de marzo. En ese país desarrollado se va a mostrar que a nivel mundial se está generalizando la pobreza, el crecimiento sin empleo y la insolidaridad social (Realidad, $\mathrm{N}^{\circ} 42$, pp. 841). Nuestra plataforma económica pudiera inspirarse en el lema de la cumbre mundial: "Las sociedades prósperas son las que existen en función del ser humano".

F. J. I. 